\title{
DILEMAS DO PENSAMENTO ECONÔMICO ENQUANTO CIÊNCIA DAS PROJEÇÕES SOBRE A ORDEM SOCIAL
}

Giancarlo Livman Frabetti ${ }^{1}$

\section{INTRODUÇÃO}

É a habilidade humana de observar e inteligir o mundo que também nos capacita, de certa forma, a projetar o presente em um plano futuro ideal, no qual nos imbuímos do poder de antever os desdobramentos das condições postas na atualidade. A bola de cristal da ciência é feita de razão e de empiria e, precisamente por ter sido forjada nesses materiais, é ela que nos encoraja a ter certa confiabilidade nos possíveis cenários apresentados. A Economia Política, nascida dos métodos das ciências da natureza para dar conta de entender a organização da sociedade sob a perspectiva dada pela sua base econômica, ocupou um lugar particular na divisão do trabalho científico, devido à sua inclinação a tecer prognósticos sobre a sociedade e, diante destes, recomendar formas de profilaxia ou de medicação para os problemas encontrados.

Em que pesem os muitos discursos de pretensa neutralidade e objetividade proferidos ao longo história do pensamento econômico e dos seus fundamentos teórico-metodológicos, a capacidade presciente da Economia Política jamais esteve, porém, apartada do papel exercido por esta ciência na formação de concepções e na orientação de decisões tomadas pela sociedade no presente: a lógica concreta do materialismo dialético nos sugere que não há prospecção ideal feita de modo absolutamente livre de um projeto de classe. Deve-se notar que, no debate clássico entre economistas políticos como Smith, Ricardo e Malthus, as projeções das condições observadas na sociedade industrial inglesa ora afirmavam, ora negavam a plena funcionalidade da relação entre oferta e da demanda como mecanismo para se alcançar estabilidade e harmonia sociais. A crítica da economia política efetuada por Marx, ao seu turno, propôs testar os termos explicativos do funcionamento dessa sociedade mediada pelos mecanismos de mercado para, precisamente, encontrar a lógica das tensões e contradições da sua disfuncionalidade e, com isso, ser capaz de antever o outro dessa mesma sociedade convalescente.

Buscamos, neste artigo, discutir acerca da capacidade prospectiva do pensamento econômico, sob a perspectiva da diferença entre as correntes de pensamento delineadas ao longo da história desta ciência. Tal capacidade prospectiva é colocada, nos termos do debate apresentado, conforme sua correspondência com as visões de positividade, de negatividade ou de alteridade em relação ao desenvolvimento de uma sociedade ordenada a partir do mercado

\footnotetext{
1 Professor Adjunto II da Faculdade de Ciências Econômicas da UFPA.
} 
que se expande e se complexifica na constituição do mundo capitalista. Para dar conta dessas três possibilidades de compreensão e de posicionamento político em relação ao modo capitalista de produção, remeteremos as diferentes correntes teórico-metodológicas do pensamento econômico, desde o nascimento da Economia Política Clássica até sua degradação na forma de Economics, ao seu conteúdo utópico, distópico ou heterotópico em relação à sociedade vigente.

\section{O NASCIMENTO DA ECONOMIA POLÍTICA E A FORMULAÇÃO DA UTOPIA LIBERAL}

As concepções de mundo e, com elas, tanto a potência quanto os limites do conhecimento e da prática social, nunca estão separadas das condições materiais de produção a partir das quais foram gestadas. $O$ processo de produção material dos meios de vida das sociedades humanas implica, mas, também, pressupõe a produção e reprodução das ideias (e, portanto, dos espíritos de uma época ou de um povo), constituindo-se, a partir do trânsito estabelecido entre esses níveis, o fundamento da divisão do trabalho, das relações sociais e, portanto, das condições de reprodução (e também das possibilidades de superação) de uma dada sociedade. Propomos esta premissa materialista e dialética da história (e da geografia), interpretada a partir do conteúdo da obra "A Ideologia Alemã" de Marx e Engels (2007 [1846]), como ponto de partida para refletirmos sobre como, desde as primeiras proposições da Economia Política clássica, foi introduzido decisiva e permanentemente, para toda a humanidade, um repertório de ideias basilares acerca de como se projetam a positividade, a negatividade e, ainda, as possibilidades da ordem econômica e social vigente.

A ideia de progresso da humanidade em direção a uma condição superior de sociedade e de domínio sobre a natureza não somente é central, mas ela se confunde com a própria origem do mundo moderno em, ao menos, dois de seus fundamentos: a constituição de um mercado mundial e também de uma racionalidade técnico-científica. Tanto as condições objetivas de intercâmbio entre indivíduos e nações, quanto os fundamentos teóricos e filosóficos da Ciência Moderna assumem, desde suas raízes mais remotas, a vocação de conduzirem 0 presente em direção a um futuro que se pretende melhor, mais harmônico ou, dito em outras palavras, ideal. É curioso notar que em 1516, o humanista inglês Thomas Moore cunhava o termo utopia - formado pelo prefixo grego de negação "ou" e pelo radical "topos" (que significa lugar) - para designar, em sua "Utopia", uma ilha na qual seus habitantes "gozavam de um sistema jurídico igualitário, liberal e justo", termo que viria a se cristalizar sob o sentido de 
identificar uma "sociedade excelente que, em razão dessa mesma excelência, não existe no mundo real" (MATOS, 2017, p. 42).

Todavia, a arrogada "missão civilizatória" do colonialismo europeu sobre os continentes americano, africano e asiático também esteve decisivamente compreendida naquilo o que Marilena Chauí (2000) identifica como a razão instrumental do conhecimento científico: o sujeito do conhecimento assumindo a postura de que conhecer - com base em um método científico pretensamente neutro e voltado para a prática - Ihe confere as condições para dominar e controlar a natureza e os outros seres humanos. Foi nesse contexto de emergência do mundo moderno (colonialista, eurocêntrico) que surgiram as primeiras proposições sobre os fenômenos econômicos para além da economia doméstica, embora não se possa afirmar que nesse tempo já houvesse sido propriamente formulado um princípio explicativo das atividades econômicas - 0 que confere a esse pensamento, denominado mercantilista, um caráter de arte empírica.

Segundo Gentil Corazza (2009), a Economia Política (termo cuja formulação atribui-se a Antoine de Montchrétien, em seu "Tratado de Economia Política", de 1615) surge na medida em que o pensamento econômico busca emancipar-se da filosofia moral e política, voltando-se, a princípio, para os interesses dos Estados nacionais em formação. Uma vez que as questões econômicas estavam postas basicamente na esfera das trocas, os mercantilistas concentravam suas investigações, por exemplo, na relação entre 0 afluxo de metais e a alta generalizada dos preços no continente europeu, desencadeada em meados do século XV. Contudo, ainda de acordo com Corazza (2009), assinala-se que nas obras de William Petty (que, em 1690, chegou a se aproximar de uma formulação teórica sobre o valor com base no trabalho, ao afirmar que a terra era mãe, e o trabalho, pai do valor) e Dudley North (em seu "Discurso sobre o comércio", de 1691), já se encontravam fundamentações metodológicas apoiadas, respectivamente, nas concepções empírico-experimental e hipotético-dedutiva de ciência.

Mas é como parte do conjunto de transformações políticas, econômicas, sociais e culturais compreendidas pelo lluminismo europeu (com sua confiança na razão enquanto instrumento de transformação do destino da humanidade) que se cristaliza definitivamente a possiblidade do método científico, oriundo das ciências da natureza, vir a fundamentar a construção de uma base teórica explicativa para os fenômenos sociais. Tendo como modelo de ciência a física newtoniana e sua busca pelas leis gerais de funcionamento da natureza, que deveriam ser expressas de modo formal e abstrato, a Economia Política passaria levantar o seu questionamento central acerca do valor enquanto substância dos processos propriamente econômicos, propondo um pensamento social que se dá sob a perspectiva das leis que regem o domínio da produção e das trocas. 
Se, tal como reconhecido pelo próprio Marx, é no "Quadro Econômico" de François Quesnay (1758) que se encontra de modo pioneiro a tentativa de formulação teórica de uma ordem geral, subjacente aos fenômenos econômicos (embora essa ordem fosse tida como essencialmente natural, em função da origem do excedente ser vista exclusivamente como dádiva da natureza), é, contudo, na obra conhecida como "A Riqueza das Nações" do filósofo e economista escocês Adam Smith (publicada pela primeira vez na Inglaterra em 1776), que se encontra a formulação mais bem acabada, para sua época, de um sistema de pensamento voltado à compreensão das leis que regem a produção e a circulação das mercadorias em uma sociedade.

No pensamento smithiano transparece esse espírito iluminista que toma a razão como caminho certo para a marcha da emancipação humana em direção às liberdades individuais e a uma organização superior de sociedade. A visão de história orientada no sentido de existiriam estágios civilizacionais superiores e inferiores de organização social está presente, na obra de Smith, no entendimento de que existiriam quatro estágios do desenvolvimento social (caça, pastoreio, agricultura e comércio), e que, em cada um desses estágios, a compreensão dos métodos de produção e distribuição das necessidades econômicas seria a chave para se conceber o funcionamento das instituições e dos governos dessas sociedades (HUNT; LAUTZENHEISER, 2013).

É, porém, na teoria do bem-estar econômico e da harmonia social de Smith que reside a mais expressiva evidência de como seu pensamento se projeta em direção a uma sociedade ideal. Para ele, os "interesses privados e coletivos se articulam de maneira benéfica através do mercado, sem a necessidade de intervenção de uma instância externa aos indivíduos - noção que fica conhecida pela ideia de 'mão invisível'” (PIMENTEL, 2013, p. 58). Do interesse individual decorrem, portanto, a propensão dos indivíduos de trocarem entre si, a divisão do trabalho e a própria repartição da sociedade em classes, emergindo desses termos uma ordem social regulada pelo mercado - ordem, esta, necessariamente harmônica e que conduziria a um estágio superior de civilização. Para Smith, "os interesses privados em relação ao mercado entendido não somente como locus em que demanda e oferta se encontram, mas principalmente como operador social - geram o bem estar público" (PIMENTEL, 2013, p. 54).

Os circuitos da produção e da circulação são articulados, na teoria smithiana, a partir de um sistema explicativo da sociedade calcado em uma ordem individualista, orquestrada segundo leis próprias e que, portanto, atuam de modo independente - e contra - as formas de ordenamento centralizadas pelo Estado. Temos aqui não só a utopia do livre mercado atuando idealmente como operador social perfeito (que faz a melhor alocação dos recursos disponíveis), 
mas também o mercado como meio para se trilhar o caminho em direção ao avanço civilizatório e, portanto, ao desenvolvimento social.

\section{A PERSPECTIVA DISTÓPICA NO DEBATE ENTRE MALTHUS E RICARDO}

No período subsequente à publicação de "A Riqueza das Nações", emergiu, na prática, toda uma problemática em torno da sociedade industrial que então já havia se estruturado em suas bases fundamentais, com suas divisões de classe e suas tensões inerentes. 0 conflito de interesses entre industriais e proprietários de terra em torno das leis de cereais estava posto, bem como as evidências da precariedade das condições de vida no seio da classe trabalhadora. Se tomarmos especialmente as conclusões expostas a partir do debate entre Thomas Malthus e David Ricardo diante deste quadro social e econômico, torna-se bastante razoável afirmar que "as teorizações a respeito do destino da humanidade sob as novas condições, formuladas pela Economia Política, mais do que desalentadoras, eram apocalípticas" (SEVCENKO, 1983, p. 86).

Por meio de um método claramente hipotético-dedutivo, e aplicando a teoria do valor trabalho às condições da produção agrícola, Ricardo apontou, em sua obra "Princípios de Economia Política e Tributação", de 1817, que haveria uma tendência permanente à queda da taxa de lucro, reduzindo os estímulos para novos investimentos. Isto se daria por que, na medida em que a fronteira agrícola se expandia em direção a terras menos férteis devido ao aumento da população, os salários tenderiam a subir (em função do aumento do valor e do preço dos alimentos), pressionando os lucros dos capitalistas para baixo sem que, ao mesmo tempo, isso significasse uma melhora nas condições de vida da classe trabalhadora. Por conseguinte, Ricardo desenhava "uma perspectiva sombria para o futuro do capitalismo, já que 0 desenvolvimento econômico tenderia a corroer suas próprias bases" (CORAZZA, 2005, p. 11).

Thomas Malthus, por sua vez, além de ter apresentado uma catastrófica teoria da população (em seus "Ensaios sobre o princípio da população", de 1798 e 1803), segundo a qual o ritmo do crescimento demográfico não poderia ser permanentemente acompanhado pelo crescimento ritmo de crescimento da produção de alimentos, também formulou, nos "Princípios de Economia Política" (1820), a possibilidade de superprodução geral de mercadorias. Para Malthus, uma crise geral de superprodução pode ocorrer em função da falta de demanda efetiva para que seja consumida toda a produção. Isto se daria por conta do fato de que, de um lado, a classe trabalhadora não tinha renda suficiente para garantir a absorção da oferta, enquanto os capitalistas tenderiam a não consumir toda sua renda, por conta da sua propensão em usar 0 
dinheiro para investir na produção (cabendo, portanto, às classes improdutivas o papel de garantir essa demanda agregada) (CORAZZA, 2005).

Por conta dessa teoria da superprodução, Malthus opunha-se tanto a Smith quanto a Ricardo, os quais aceitavam o princípio de que toda produção geraria um mercado para seus produtos, assumindo-se que a moeda funcionaria apenas como meio de troca - não havendo, por isso, sentido em entesoura-la (princípio que acabou ficando conhecido como "Lei de Say", por conta do seu popularizador, o economista francês Jean-Baptiste Say) (HUNT; LAUTZENHEISER, 2013). Notamos, aqui, que a positividade introduzida pela noção de autoregulação do mercado (apontando para um ordenamento social ideal) inevitavelmente viria a encontrar o seu negativo (e sua angústia fundamental), traduzidos tanto pela teoria ricardiana da tendência de queda da taxa de lucro, quanto pela refutação malthusiana com relação à preservação do poder de compra, mediante a identidade entre oferta e demanda no mercado. No interior desse debate, a utopia do liberalismo econômico veio de encontro "ao seu gêmeo fantasmático, ao seu doppelgänger. a distopia" (MATOS, 2017, p. 45) - do prefixo grego dys, que significa "doente", "mal" e "anormal".

\section{A CRÍTICA DA ECONOMIA POLÍTICA COMO POSSIBILIDADE DE SUPERAÇÃO DA ORDEM VIGENTE}

A perspectiva distópica acerca das premissas básicas do liberalismo seria levada às últimas consequências sob a perspectiva marxiana da crítica da Economia Política, na qual, por meio da teoria do mais-valor, demonstrava-se que "mesmo numa sociedade liberal perfeita, em que todas as regras da troca são estritamente obedecidas, os capitalistas têm um modo de extrair maisvalor dos trabalhadores" (HARVEY, 2013, p. 138). O edifício teórico de Marx é concebido, em um primeiro momento, a partir da maneira como os termos da Economia Política clássica apreendem a realidade posta, dispondo estes termos de modo a funcionarem em seu estado ideal (puro) - mercado em perfeito equilíbrio, mercadorias vendidas pelos seus valores, inexistência de barreiras de acumulação, entre outros artifícios - para com isso, revelar todas as contradições inerentes, todos os lugares perturbadores aos quais a fantasia liberal de progresso social por meio do livre mercado estaria conduzindo a sociedade capitalista.

Para Marx, os limites da ordem social capitalista estariam postos por seus próprios mecanismos internos de funcionamento, os quais atuam no sentido de concentrar riqueza em um polo da sociedade, na mesma medida em que aprofundam a pobreza no polo oposto, conforme se apresenta na lei geral da acumulação capitalista ao final do Livro I de "O Capital" (publicado 
pela primeira vez em 1867). E, todavia, em contradição com a própria polarização reproduzida e ampliada pela sociedade de classes, os circuitos da realização do valor, por sua vez, constituem um organismo doente e em permanente desequilíbrio, que sistematicamente mina as bases do crescimento que ele mesmo pressupõe de modo vital.

Mas, na mesma medida em que a perspectiva crítica de Marx acerca da utopia central do liberalismo delineia as vias da sociedade capitalista em direção à sua dissolução, revelando, portanto, sua disfuncionalidade (muito mais do que seu modo de funcionamento), colocava-se imediatamente no horizonte do seu pensamento 0 projeto de emancipação da classe trabalhadora. Ao contrário, portanto, das projeções de emancipação propostas nos programas dos chamados socialistas crítico-utópicos, os quais teriam concebido suas ideias de sociedade superior a partir de um "entendimento impreciso acerca do antagonismo de classes", buscava-se construir, desde o "Manifesto Comunista" de Karl Marx e Friederich Engels (1848), uma perspectiva crítica da sociedade capitalista na qual a atividade social não estivesse substituída pela imaginação pessoal, nem "as condições históricas de superação por condições fantásticas" (MARX; ENGELS, 2005 [1848], p. 67).

Essas objeções de Marx e Engels ao pensamento que idealiza a sociedade superior, sem se dar conta da necessidade da crítica aos fundamentos da sociedade presente a fim de se ter clareza das condições históricas de sua superação, se fizeram presentes, de modo subjacente, em todo programa subsequente de pesquisa e reflexão por meio do qual se realizaria a crítica da economia política. A lógica dialética e materialista propõe, assim, o que poderia se chamar de utopia concreta, ou de uma "utopia com os pés no chão", na expressão de Ester Limonad (2018): uma projeção em direção ao futuro que não almeja atingir metas préestabelecidas (abstratas), mas que se funda nas condições postas pelo presente para tentar antever as brechas, ou ainda, as contradições sistêmicas internas que permitiriam a superação da própria ordem vigente.

\section{A DESTILAÇÃO DA ECONOMIA POLÍTICA PELO PENSAMENTO NEOCLÁSSICO}

Mesmo diante das evidências empíricas e da consistência das formulações teóricas indicando, a partir da Economia Política clássica, que a ordem social e econômica capitalista portava, em seus próprios termos, o sentido de sua crise imanente (assim como as possibilidades de sua superação), as correntes cientificistas na passagem do século XIX para o XX não hesitaram em reformular as premissas idílicas da utopia liberal, individualista, mecanicista, anunciando a nova escalada do processo produtivo em um mundo predestinado ao constante crescimento, diante 
dos recursos virtualmente ilimitados postos ao alcance do neocolonialismo. De acordo com Sevcenko (1983), tomaram corpo e difundiram-se, sob esse contexto, tanto o organicismo spenceriano e quanto a solidariedade comteana, ambos ressaltando a interdependência entre os componentes do organismo social, bem como das várias sociedades e nações entre si.

É na esteira dessa visão burguesa acerca do projeto de absolutização das leis do livre mercado e do progresso técnico-científico que, particularmente, no interior do debate econômico, os propositores da teoria marginalista viriam a realizar a definitiva destilação da Economia Política, excluindo seu conteúdo propriamente político para tratar de maneira estritamente formal as questões delimitadas pelo campo da Ciência Econômica (ou, apenas, Economics). Conforme afirma Letícia Pimentel (2013), embora as obras fundantes do marginalismo econômico (representadas por Stanley Jevons, Carl Menger e León Walras) tivessem conservado o princípio smithiano de que, no funcionamento do mercado, subjaz uma ordem auto-regulada e, portanto, natural e imutável, estes autores, contudo, reduziram o mesmo princípio, na medida em que abandonaram decisivamente a premissa de que este mercado atuaria como ordenador social (estabelecendo as classes sociais e seus respectivos interesses, potencialmente conflitantes entre si).

Para afirmarem o caráter positivo da Ciência Econômica, os marginalistas assumiram a postura de refutar definitivamente a teoria do valor trabalho, substituindo-a pela ideia de valor utilidade: todo conhecimento econômico poderia ser reduzido a uma relação absolutamente abstrata entre agentes individuais, cujas decisões, no ambiente de mercado, seriam pautadas racionalmente pelo objetivo último de se obter o maior ganho possível, mediante o menor dispêndio possível de recursos (HUNT; LAUTZENHEISER, 2013). A postura anti-histórica proposta pelos marginalistas reverberava a premissa de que haveria um necessário equilíbrio entre as partes constituintes do organismo social, depositando-se uma confiança inabalável na harmonia sistêmica da sociedade organizada a partir da ação individual. Perceba-se, ainda, que esta recusa dos economistas neoclássicos em relação à história (e também ao espaço, como bem observou Milton Santos, 2012), anunciando a morte da Economia Política e reduzindo toda possibilidade de explicação econômica ao formalismo dos modelos matemáticos, resulta igualmente em uma postura anti-utópica, como se jamais pudesse existir algo além daqueles princípios orgânicos bem definidos e definitivos na sociedade (postura essa que, muitas décadas depois, seria ruminada pela ideia de "fim da história", nas palavras de Francis Fukuyama). 


\section{O PRAGMATISMO KEYNESIANO E O PAPEL DO PLANEJAMENTO}

Contudo, diante de um intenso processo de concentração e centralização do capital, bem como diante das incertezas causadas pela crise geral de reprodução do capitalismo a partir do fim da década de 1920, tornou-se cada vez mais evidente a fragilidade das bases teóricas e práticas do mercado mundial tal como elas então se apresentavam. Nesse contexto, a "Teoria Geral do Emprego, do Juro e da Moeda" (de 1936), do economista britânico John Maynard Keynes, empreendia o projeto de salvar o mundo capitalista de sua destruição por meio da proposição de que o Estado deveria cumprir o papel de garantir a absorção da demanda agregada, a qual não poderia decorrer exclusivamente dos mecanismos da oferta e da demanda. A contestação do modo como os economistas neoclássicos aceitaram e absolutizaram o princípio de estabilidade antevisto na "Lei de Say" se daria, portanto, por meio do pragmatismo keynesiano, que terminou por elaborar uma teoria na qual se negava a automaticidade do mercado, porém mantendo "a fé na teoria da distribuição baseada na produtividade marginal e a fé na eficiência alocativa do mercado" (HUNT; LAUTZENHEISER, 2013, p. 761).

A Ciência Econômica, proposta por Keynes enquanto uma "ciência moral" (CORAZZA, 2009) viria a se entranhar de maneira sem precedentes na estrutura do poder dos Estados nacionais no mundo capitalista, pautando políticas calcadas nos ideais e nas teorias da modernização e do desenvolvimento, bem como no papel do planejamento - ideias, estas, que passariam a constituir os pilares característicos do modo de organização social e econômica dos territórios ao longo do século XX. Ao contrário, portanto, da visão anti-histórica e calcada no individualismo metodológico proposta pelos marginalistas, a fundamentação keynesiana para 0 modo de se pensar a relação entre economia e território certamente implica uma forma de projeção do presente em direção ao futuro, contudo tais projeções se dão de maneira necessariamente pragmática, uma vez que são orientadas pela racionalidade planificadora e econômica centralizada no Estado e que concebe a industrialização como elemento impulsionador das etapas evolutivas de uma nação. No seio desse debate sobre a modernização, surgem os contrapontos críticos propostos pelas teorias do subdesenvolvimento e da dependência, as quais, contudo, de maneira geral, retomam a perspectiva da planificação e da indústria, porém reorientando-a no sentido de se passar a pensa-las enquanto fatores de propulsão do processo de emancipação nacional em relação à sua condição subalterna no sistema-mundo.

O século XX foi, portanto, um período em que emergiu decisivamente uma perspectiva pragmática no modo de se projetar da sociedade, reduzindo os horizontes dessa prática à forma 
dada pela racionalidade tecnocrática do planejamento. Tal perspectiva redutora cristalizou-se nos projetos imperialistas e nacionalistas do período em questão: sociedades nas quais a utopia aparece invertida, usada como estratégia ideológica para se esconder a barbárie instaurada nessas mesmas sociedades. Diante da forma industrial assumida pelas guerras entre as grandes potências mundiais e da emergência dos regimes políticos voltados para o controle social, define-se o quadro alarmante que fez desse contexto histórico um momento particularmente profícuo sob o ponto de vista da elaboração das distopias, sobretudo das distopias literárias, cuja forma definitiva foi estabelecida nas obras de autores como Aldous Huxley ("Admirável Mundo Novo", de 1932), George Orwell (“1984”, publicado em 1949) e Anthony Burgess ("Laranja Mecânica", de 1962).

Seja pela imposição de um estado bem-estar permanente alcançado pela eliminação das emoções humanas, seja pela presença do "Grande Irmão" em todos os âmbitos da consciência individual e da vida privada ou, ainda, pela tentativa de ressocialização do indivíduo delinquente em uma sociedade doente, o exercício de se projetar o presente no futuro, exacerbando sua disfuncionalidade, tornou-se uma forma particular (e significativamente popularizada) de entendimento do mundo. Embora voltadas sobretudo a uma crítica da modernidade feita pela perspectiva do poder, muito mais do que das condições de produção, essas obras legaram, porém, a possiblidade de se fazer o exercício de leitura do mundo presente não por meio do seu funcionamento, mas por meio das suas disfuncionalidades, abrindo um campo de possiblidades para se pensar a relação contraditória entre as ideias e as práticas de ordenamento da sociedade.

\section{O FIM DA HISTÓRIA E A FÉ NAS HETEROTOPIAS}

Esta breve retrospectiva acerca das oscilações entre as positividades, as negatividades e as possibilidades contidas nas projeções do pensamento econômico sobre a ordem social, evidentemente, não estaria concluída se não nos detivéssemos, por fim, nesse momento profundamente perturbador representado pela emergência e consolidação do neoliberalismo como doutrina hegemônica no mundo capitalista, o qual, a partir de então, passou a ser identificado sob o apologético rótulo da globalização. 0 processo de mundialização do capital na passagem para o século XXI tanto requereu quanto ensejou a condição hegemônica assumida pelo pensamento econômico ortodoxo originário da Escola de Chicago. Nesse movimento, os fundamentos da economia neoclássica e de sua uma concepção anti-histórica de sociedade são retomados, porém, agora, sob os ditames de um novo projeto, que é o de transferir o poder 
decisório do planejamento centralizado para as mãos do capital monetário descentralizado, supostamente sem pátria e sem partido, cuja racionalidade se fundamenta única e exclusivamente na busca incessante pela oportunidade.

A ciência do comportamento dos agentes econômicos no mercado delimita, pretensamente, um estado de sociedade inescapável, no qual os territórios tornam-se reféns de um mecanismo decisório imposto pela capacidade do capital monetário circular livremente pelo mundo, movido apenas pela procura por condições circunstanciais de rendimento. A perspectiva posta pelo receituário neoliberal é a de que, nacionalmente, não resta nada além da obrigação de implementar medidas que visem garantir um ambiente de estabilidade para a atuação do capital monetário, enquanto aos setores produtivos da sociedade resta lidar com as instabilidades sistêmicas do processo de acumulação por meio das reestruturações produtivas e organizacionais do capital.

Paralelamente a este contexto de horizonte fechado imposto pela absolutização das regras do livre mercado, nota-se, do ponto de vista das concepções de mundo, um desencantamento profundo com aquilo que veio então a ser chamado de "grandes teorias", ou "grandes sistemas de pensamento", que passaram a ser tidos, a partir da perspectiva genericamente identificada pelo pós-modernismo, como totalizantes e rígidos (HARVEY, 2008). No campo progressista do pensamento, as questões postas pelo debate sobre a alteridade erguem-se diante da pretensa capacidade presciente das projeções feitas desde a Economia Política no século XIX, mas também pelos planos da Ciência Econômica, da Geografia e da Arquitetura ao longo do século XX. Este processo de desconstrução dos edifícios teóricos do pensamento ocidental abriu caminho para a (re)elaboração e (re)valorização de práticas destoantes da ordem vigente, cujas possibilidades se colocam em escala local e organizadas na forma de redes.

Acerca da elaboração intelectual de tais práticas, cabe mencionar certo paralelo entre as obras dos filósofos franceses Henri Lefebvre (2008) e Michel Foucault (1984), nas quais ambos chegam a formular, ainda que por vias completamente distintas, e com objetivos igualmente diferentes, a noção de heterotopia. Esta pode ser lida como o futuro se fazendo presente na forma do outro: os espaços de alteridade enquanto campos de possiblidades em relação à ordem vigente. Todavia, embora a expressão "heterotopia" esteja sendo cada vez mais amplamente difundida na Geografia Urbana, cabe assinalar certa imprecisão do seu uso, acarretada pela ampla (e heterogênea) gama de situações empíricas circunscritas a partir desse conceito, como afirma Peter Johnson (2013) a respeito da influência dessa noção a partir da obra de Foucault. Acrescentamos, ainda, que a desconfiança em relação aos discursos e às 
grandes narrativas parece também conduzir a um completo descrédito quanto ao potencial emancipatório de certos fundamentos teóricos pressuposto nas utopias, mas também uma provável banalização (e neutralização) do efeito potencialmente esclarecedor das distopias.

\section{CONSIDERAÇÕES FINAIS}

A projeção do presente no futuro, ou seja, as concepções ideais de mundo formuladas a partir da observação e da leitura das condições materiais de produção tal como elas se apresentam, constituem um exercício tanto de conhecimento quanto de intervenção (ou, ainda, de transformação) social. A Economia Política, enquanto ciência e arte a uma só vez, teve um papel importante a desempenhar nesse exercício, expressando, por meio das disputas entre suas distintas correntes teórico-metodológicas, tanto a perspectiva de um horizonte de absoluta harmonia prometido pela razão individualista, quanto a inerente tendência de instabilidade (ou mesmo o inexorável caminho rumo ao colapso) da sociedade capitalista.

O pensamento econômico do século XX, por sua vez, impôs, de maneira geral, uma racionalidade pragmática quanto ao modo de lidar com as instabilidades inerentes à ordem vigente, passando pelo florescimento das práticas de planejamento centralizado, mas culminando em uma aceitação acrítica do mercado como mecanismo inquestionável de alocação dos recursos. Longe de serem concepções inocentes e desinteressadas, estas proposições estiveram na base da formulação de projetos concretos de território e de sociedade, inclusive vindo a desabar diante dos desafios postos pela prática a essas mesmas sociedades.

E, embora a consciência crítica mais contemporânea tenha, em consequência do seu desencantamento, postulado a perspectiva de que ordem vigente pode ser subvertida por meio da ação localizada em nichos de resistência, sobrevive de maneira surpreendente a noção geral de que uma sociedade se desenvolve na medida em que vence degraus em direção a um nível maior de relação entre os movimentos de especialização da produção e de aprofundamento do intercâmbio. Resta ainda hoje, portanto, lidar com a intrincada questão levantada pelos pressupostos e pelo sentido dos conteúdos propriamente econômicos do conceito de desenvolvimento, o qual encontra sua expressão geográfica no conceito de desenvolvimento regional - problemática que se coloca como plano de pesquisa em aberto e que precisa urgentemente ser conduzido no sentido de dar conta do modo como este pensamento econômico nascido no centro do sistema capitalista veio a incidir sobre o pensamento social brasileiro, bem como sobre as estratégias de desenvolvimento nacional. 


\section{REFERÊNCIAS BIBLIOGRÁFICAS}

CHAUÍ, Marilena. Convite à filosofia. São Paulo: Ed. Ática, 2000.

CORAZZA, Gentil. Ciência e Método na História do Pensamento Econômico. Revista de Economia, v. 35, n. 2 (ano 33), p. 107-135, maio/ago. 2009.

CORAZZA, Gentil. Malthus e Ricardo: duas visões de economia política e de capitalismo. Cadernos IHU Ideias. Instituto Humanitas UNISINOS, São Leopoldo, RS, ano 3 - n 39. 2005.

HARVEY, David. Condição Pós-Moderna: uma pesquisa sobre as origens da mudança cultural. São Paulo: Edições Loyola, 2008.

HARVEY, David. Para entender O Capital (Livro I). São Paulo: Boitempo, 2013.

HUNT, E. K.; LAUTZENHEISER, Mark. História do pensamento econômico. Rio de Janeiro: Elsevier, 2013.

JOHNSON, Peter. The Geographies of Heterotopia. Geography Compass, 7/11 (2013): 790803, 10.1111/gec3.12079.

LEFEBVRE, Henri. A revolução urbana. Belo Horizonte: Ed. UFMG, 2008.

LIMONAD, Ester. Uma utopia com os pés no chão: algumas considerações sobre práticas espaciais transformadoras. Novos Cadernos NAEA, v. 21 n. 2, p. 79-92, maio-ago 2018.

MARX, Karl; ENGELS, Friederich. Manifesto comunista. São Paulo: Boitempo, 2005.

MARX, Karl; ENGELS, Friederich. A ideologia alemã. São Paulo: Boitempo, 2007.

MATOS, Andityas Soares de Moura Costa. Utopias, distopias e o jogo da criação de mundos. Rev. UFMG, Belo Horizonte, v. 24, n. 1 e 2, p. 40-59, jan./dez. 2017.

PIMENTEL, Letícia Barbosa. 0 projeto de ciência moderna e os caminhos epistemológicos da economia: marginalismo e Materialismo histórico dialético. (Dissertação de Mestrado). Universidade Federal do Rio de Janeiro, Instituto de Economia. Rio de Janeiro, 2013.

SANTOS, Milton. Por uma economia política da cidade. São Paulo: Edusp, 2012.

SEVCENKO, Nicolau. O Cosmopolitismo pacifista da Bele Époque: uma utopia liberal. Revista de História. São Paulo: n. 114, p. 85-94, 1983.

Recebido para avaliação em Maio de 2019.

Aceito para publicação em Agosto de 2019. 


\section{DILEMAS DO PENSAMENTO ECONÔMICO ENQUANTO CIÊNCIA DAS PROJEÇÕES SOBRE A ORDEM SOCIAL}

\section{RESUMO}

Este artigo apresenta uma discussão teórica sobre a vocação da Economia Política enquanto ciência de elaborar projeções da sociedade a partir da leitura dos problemas econômicos verificados no presente. A partir das distintas perspectivas teórico-metodológicas dos trabalhos clássicos da Economia Política, identificamos as possiveis visões sobre aprofundamento das relações sociais em uma sociedade de mercado, oscilando dialeticamente entre a utopia, a distopia e a possibilidade de alteridade da realidade observada. Avançando nesse debate até chegarmos ao pragmatismo econômico do século XX e à desilusão quanto à possibilidade de superação estrutural do capitalismo própria do pós-modernismo, concluímos nosso raciocínio apontando que o conceito de desenvolvimento constitui um elemento central na tarefa de se projetar o presente em direção ao futuro, devendo portanto, ser superado criticamente.

Palavras-chave: Economia Política, utopia, distopia, heterotopia.

\section{ABSTRACT}

This paper presents a theoretical debate concerning the typical vocation of the Political Economy science for elaborating projections of the society taken from the economic problems identified in the present. Concerning the distinct methodological and theoretical perspectives of the classic Political Economy authors, we present a discussion on the different views on how the production and trade relations evolve in the capitalist society, oscillating between utopias, distopias and heterotopias. As we go further on this debate, discussing the economical pragmatism of the twentieth century, as well as the typical desilusion of the current postmodern society, we point out that the concept of economic development consists in a central element for the attempts to project the present into the future, and for such reason, this concept must be critically overcome.

Key words: Political economy, utopia, distopia, heterotopia. 